\title{
A encenação de Gerald Thomas: o espectador desestabilizado
}

\author{
ROBSON ROSSETO 1
}

\footnotetext{
Robson Rosseto é Mestre em Teatro pela Universidade Estadual de Santa Catarina/UDESC e docente da Universidade Estadual do Paraná-UNESPAR, campus Faculdade de Artes do Paraná-FAP. Integrante do Grupo de Pesquisa Arte, Educação e Formação Continuada-UNESPAR/FAP e membro do GT Pedagogia das Artes Cênicas da Associação Brasileira de Pesquisa e Pós-Graduação em Artes Cênicas/ABRACE. Atualmente, cursa Doutorado no Programa de Pós-Graduação em Artes da Cena, do Instituto de Artes da Universidade Estadual de Campinas-UNICAMP. rossetorobson@gmail.com
} 


\section{RESUMO}

Este trabalho objetiva apresentar uma reflexão sobre os processos estéticos do encenador Gerald Thomas. O texto aponta a concepção de Thomas para a criação cênica a partir de fragmentos textuais e da intertextualidade, aglutinando/justapondo elementos da cena com a narrativa. A reflexão identifica o papel do espectador como um sujeito desestabilizado pela encenação.

\section{- PALAVRAS-CHAVE}

Gerald Thomas, espetáculo, espectador.

\section{- ABSTRACT}

This work presents a reflection on the aesthetic processes of the director Gerald Thomas. The text points to the conception of Thomas for the scenic creation from textual fragments and intertextuality, agglutinating/juxtaposing elements of the scene with the narrative. The reflection identifies the role of the spectator as a destabilized subject by scenario.

\section{- KEYWORDS}

Gerald Thomas, spectacle, viewer.

Discorrer sobre a cena teatral contemporânea tornou-se uma árdua tarefa nos últimos tempos. Encenadores que dominam códigos estabelecidos e os transgridem revelam valores na encenação que necessitam de estudos dirigidos para um melhor entendimento sobre o teatro. O texto dramático continua sendo um dos fundamentos do teatro, mas deixou de ser o fundamento principal. A liberdade de desconstruir e reconstruir, marca da encenação contemporânea possibilita a exploração desses valores numa viagem para dentro da obra. São procedimentos e códigos novos que desvendam novos horizontes.

Gerald Thomas (1954) é um artista em constante diálogo com a arte e seus procedimentos contemporâneos. Suas encenações estão alicerçadas na incoerência e no caos. Seu teatro tem o vigor da ruptura com padrões aristotélicos consagrados na dramaturgia. A palavra é só mais um dos elementos que utiliza para compor a cena. E não se trata de uma palavra qualquer, mas um diálogo filosófico sobre o homem e a arte, marcado por citações de filósofos, artistas plásticos, escritores e dramaturgos. A partir de uma intensa intertextualidade, o encenador combina as ações fragmentadas e repetitivas de seus atores com a música, a luz e o espaço. Ele transita com grande desenvoltura por entre as linguagens artísticas, fundindo-as, desestruturando-as, desconstruindo-as para dar forma e conteúdo a um novo teatro, a uma nova dramaturgia. É possível perceber tais afirmações na crítica teatral de Macksen Luiz do Rosário Filho no Jornal do Brasil sobre o espetáculo $N x W^{2}$ de Gerald Thomas.

É dentro de uma estrutura cênica que se mistura tal qual a escrita - não há dissociação entre o papel e o palco, aquilo a que se assiste é paralelo ao processo dramatúrgico - que se estabelece o registro da encenação. A inexistência de um texto com conformações dramáticas que pretenda contar uma história corresponde à ausência

2 O espetáculo foi baseado em protestos do filósofo Friedrich Nietzsche contra o músico Richard Wagner. 
de evolução narrativa. O fragmento é o padrão de medida nas repetições de uma mesma cena, na inversão das palavras, em frases e ruídos, descoordenados e no uso da música. Gerald Thomas multiplica imagens em quadros (cenas quase autônomas) e procura jogar o espectador dentro dessas imagens em movimento (2000).

A encenação de Thomas não pretende organizar a engrenagem teatral do sentido da representação, não é um processo de leitura e interpretação cênica de um texto dramático. Ele não se limita a ordenar os elementos cênicos, mas sistematiza concepções significativas, construindo um modo específico de criar a cena. Desta forma, o discurso cênico torna-se a maneira pela qual o encenador organiza a representação no espaço e no tempo em conformidade com os intérpretes numa lógica diferenciada. Por exemplo, Cibele Forjas (2010) relata a sua experiência ao assistir pela primeira vez a um espetáculo de Thomas, Electra com Creta, em abril de 1987, na qual descreve o que presenciou, especialmente sobre a iluminação do espetáculo:

A luz lateral, em corredores, fazia aparecer e desaparecer personagens e imagens, textos ditos como torrentes de palavras, ou em citações curtas, e as mesmas imagens/cena eram repetidas ora aqui, ora ali, formando um quebra-cabeça. [...] Nunca tinha visto uma luz assim. Luz diretora. Luz texto. [...] Como uma sinfonia minimalista, o roteiro de luz revelava três partituras espelhadas, onde sequência de ações se repetiam, se multiplicavam (FORJAS, 2010, p. 156).

Neste caso, a iluminação tornou-se um elemento de igual representatividade comparado ao texto, não era uma luz com referências no conceito do teatro dramático no sentido de ambientar a cena, era uma "luz texto", "luz diretora" como Forjaz afirma. De fato, a iluminação concebida desta maneira, a partir do jogo de novas relações que se estabelece na encenação, traz uma dimensão de cores, cortes, ritmos, sombras, na qual os efeitos irão traçar um discurso visual, fundado no não verbal, tornando-se um elemento de grande eficácia narrativa.

O que define o teatro de Thomas é a forma, ou melhor, é o modo de como a informação é tratada na cena, há uma exploração exaustiva de outros elementos cênicos junto com a construção da dramaturgia. O encenador não trata o texto como uma escrita linear do drama, a partir do conceito clássico discutido e explicitado pelo pesquisador Peter Szondi (2001). O teatro de Gerald Thomas

[...] começou a ser feito de fragmentos sem unidade aparente. Os espectadores foram convidados a mergulhar no meio de dezenas de citações de filósofos, artistas plásticos, escritores, cineastas, músicos, todos democraticamente fervidos no caldeirão de referências do diretor. Marcel Duchamp, Samuel Beckett, Tadeusz Kantor, os dois Richards - Wagner e Foreman - Dante Alighieri, Christo e Cristo, Francis Bacon, James Joyce, Proust, Shakespeare e Haroldo de Campos passaram a ser 'incestuados' na ópera seca de Gerald Thomas (FERNANDES e GUINSBURG, 1996, p. 23).

Nesse sentido, Sílvia Fernandes e Jacó Guinsburg (1996) ainda acrescentam que a leitura da cena, nesta concepção, não é fácil, pois os elementos que compõem a encenação são justapostos por fragmentos de textos, imagens e personagens que 
não revelam seu grau de parentesco. Ao mesmo tempo, várias histórias compõem o espetáculo, embaralhando propositalmente épocas e personagens, técnica que Thomas denominou de incesto.

Através da justaposição de várias personagens, o encenador consegue criar novas perspectivas de visão de uma mesma figura dramática. O procedimento da intertextualidade é marcante em suas montagens, exigindo uma reorganização dos fatos em cena a partir de uma herança cultural que o espectador adquiriu. Portanto, são espetáculos que supõe uma plateia iniciada nos códigos de leituras anteriores. Desta forma, a memória do espectador é convocada a todo tempo.

Mas, por outro lado, se o espectador no ato da leitura traz pouco ou nenhum conhecimento histórico das proposições colocadas na cena para delinear possíveis relações, mesmo assim, obviamente, ele irá fruir a encenação ao seu modo. Ora, se é o espectador quem na realidade cria o espetáculo, ele precisa estar atualizado com o que ocorre nas encenações, para onde caminham, suas propostas, etc. Sobre a plateia, Anne Ubersfeld afirma:

[...] é o espectador, muito mais que o encenador, quem fabrica o espetáculo, pois ele tem de recompor a totalidade da representação em seus eixos, o vertical e o horizontal ao mesmo tempo, sendo obrigado não só a acompanhar uma história, uma fábula (eixo horizontal), mas também a recompor a cada momento a figura total de todos os signos que cooperam na representação. Ele é forçado a envolver-se no espetáculo (identificação) e a afastar-se dele (distanciamento). Não há, é certo, outra atividade que exija semelhante investimento intelectual e psíquico. Daí advém, sem dúvida, o caráter insubstituível do teatro e sua permanência em sociedades tão diferentes e sob formas tão variadas (UBERSFELD, 2005, p. 20).

Assim sendo, a recepção do público envolve imaginação, percepção, emoção, intuição, memória e raciocínio. Ser espectador é uma prática analítica que está direcionada pela preocupação de desvendar sentidos, ou ainda, dar significados e fazer ressonâncias ao acúmulo de conhecimentos artísticos e estéticos, aberto a uma leitura historicizada. Portanto, não há uma única interpretação sobre um determinado espetáculo, o que importa é o diálogo que o espectador trava com a cena.

O projeto de Thomas se consolidou por colocar nos espetáculos várias lógicas em movimento; a desconstrução do texto, sua marca mais conhecida, coloca um convite para o espectador, o de organizar a narrativa. Desta maneira, a palavra dita por um ator se estabelece de outro modo, pois este a ressignifica, a partir da sua partitura corporal articulando-a com os elementos sígnicos colocados na cena.

[...] o ator, geralmente, se prende de uma forma desesperada a uma coisa chamada texto. Isso quer dizer que o ser humano se prende desesperadamente a uma coisa chamada palavra. Por quê? Não sei. Talvez porque seja uma forma mais imediata de identificação das coisas. E isto é um perigo constante para o artista: o de virar um cicerone descritivo de assuntos realistas. [...] não perco muito tempo com o texto. Ele me serve como um elemento tão forte ou tão fraco quanto a luz, quanto a expressão isolada de um ator, quanto uma música etc. Quando o meu texto é concebido ele tem que ser enxergado como um elemento concretista. Uma sílaba dita por alguém passa a ter importância onomatopaica porque aquele som naquele 
momento invoca coisas mais interessantes do que uma palavra 'aguardada' pela platéia (THOMAS, 1996a³ , p. 29- 30).

De acordo com o encenador, a palavra tem a mesma importância em comparação com qualquer outro elemento da engrenagem teatral. Nesta configuração, o texto dificilmente irá atender às expectativas que delineiam, muitas vezes, o gosto do espectador. Ao contrário, as proposições de Thomas promovem o rompimento de barreiras e o cruzamento de fronteiras, uma vez que a estética teatral que ele preconiza tende a quebrar/ romper as expectativas do espectador. Alberto Guzik relata que Thomas

\begin{abstract}
Capta de todos os lados, de todo tipo de fonte, da política à literatura, do surrealismo ao minimalismo, da música à filosofia e ao cinema, as informações que the interessam. Leva-as para a cena depois de cozê-las no forno íntimo de seu universo de imagens. O palco, nesse teatro, é uma tela, um filtro das emoções e percepções do artista. [...] Exibe visões, frases, fragmentos, num carrossel veloz, destinado a atordoar o espectador (GUZIK, 1996, p. 199).
\end{abstract}

O encenador confirma sua condução: "Se um espetáculo meu significar uma única coisa eu me retiro de cena ou me suicido" (THOMAS, 1996a, p. 33). Por certo, a obra de Thomas deseja perturbar o espectador, desestabilizá-lo. Inclusive, segundo Fernandes (1996), com frequência a voz de Thomas interfere no momento da cena, assim como a própria presença do encenador no palco (em algumas situações específicas), mas sempre sem apresentar nenhum personagem. $O$ Gerald Thomas que adentra no palco, na maioria das vezes com monólogos, profere comentários do espetáculo, da personagem, produzindo um reflexo verbal do seu próprio universo imaginário.

Os espetáculos que Thomas encenou desde a década de 1980 estão alicerçados numa estrutura teatral muito semelhante às discussões da atualidade sobre 0 teatro: o pós-dramático. $O$ conceito pós-dramático foi cunhado pelo crítico e professor alemão Hans-Thies Lehmann. $\mathrm{O}$ autor analisa a evolução das formas cênicas e textuais do teatro após o século XX e aponta o surgimento de um novo tipo de teatro que coloca novos paradigmas na cena e na dramaturgia. Lehmann (2007) constata que o texto não é mais o elemento a orientar as montagens, efeito provocado pelo teatro de estética pós-moderna dos anos 1960 e que começa a se estabelecer, sobretudo, na década de 1980.

Lehmann não cria um conceito para ser aplicado nesse ou naquele teatro, apenas fornece uma estrutura teórica para que se entenda uma cena complexa que já não cabe mais nas relações clássicas do teatro. $O$ texto é fracionado ou eliminado de vez e os elementos periféricos do teatro tomam o núcleo da cena. Com efeito, desde as primeiras montagens de Thomas identificam-se elementos de seu trabalho integrados às novas configurações e aos novos conceitos da representação teatral marcados pelo hibridismo e pela intertextualidade.

Essas inovações no palco colocavam a obra teatral de Thomas sob olhares críticos e percepções negativas. A imprensa brasileira, com recorrência, apresentou críticas severas ao trabalho dele, especialmente sobre a quase extinção da palavra em suas encenações. Manchetes como "Teatro da palavra versus teatro da imagem"

3 Fala de Gerald Thomas na entrevista dada ao Cadernos do SESC em janeiro de 1994. 
eram trazidas à tona compondo o debate sobre a concepção teatral de Thomas. Entretanto, ele rebatia as críticas:

Se eu abro a cortina, e em cena está uma mesa vazia, com um prato de comida ainda quente, sem um só som, e deixo a imagem lá por vários minutos, o que o espectador vai fazer dessa informação? Vai olhar o tableau e não pensar nada, ou transformará essa imagem em palavras dele, ou construirá ainda uma terceira simbologia constituída de palavras, impressões e outras várias coisas? Como irá se dar a reflexão do espectador sobre essa cena? É impressionante estarmos varando mais um ano e o imbecil blá-blá-blá sobre a palavra ou a imagem no teatro ainda ser um tópico na cabeça (ou do pouco que resta dela) de alguns que se dizem teatrólogos (THOMAS, 1996b4, p. 69).

Thomas contestou, por muitas vezes, de forma rígida, os artistas brasileiros. 0 teor de suas críticas era direcionado para as produções nacionais que se pautavam no conceito de teatro construído desde Aristóteles, aquele teatro que privilegia a dinâmica do conflito, o texto dialogado, o ator identificado e uma representação das ações e reações humanas. Contudo, reitera-se, o propósito de Thomas estava justamente na contramão, uma vez que o seu trabalho instaura um movimento cênico não contínuo, feito de fragmentos sem nenhuma unidade aparente.

Os textos mordazes sempre fizeram parte da vida e obra de Gerald Thomas, tanto os escritos produzidos por ele quanto as matérias jornalísticas com referência ao trabalho dele. Apesar das polêmicas públicas que configuraram o percurso histórico deste artista, a sua produção foi e ainda continua sendo objeto de estudo para pesquisadores de teatro e da arte de forma geral.

Em relação à construção da personagem, os procedimentos utilizados por Thomas conferem ao ator uma difícil tarefa. Pois uma obra que preconiza um emaranhado de vozes, personagens que trazem à tona fatos aleatórios com saltos temporais e associações aparentemente desconexas, coloca o ator numa responsabilidade de criar a personagem e uma interpretação a partir das referências históricas apresentadas pelo encenador e das pistas narrativas colocadas em jogo para o processo criativo. Nesse sentido, as técnicas para a interpretação do ator que alicerçaram o teatro dramático não são utilizadas em sua totalidade.

As revoluções dos processos de preparação do ator a partir dos estudos de Stanislavski (1863-1938) abriram horizontes exaustivamente explorados por criadores das artes cênicas. A base do seu método é a vivência do ator em cena a partir de emoções autênticas, numa atuação verossímil. Deste modo, o ator usa sua própria "memória afetiva" na busca da emoção da personagem. Para tanto, o trabalho emerge por meio de uma análise minuciosa da dramaturgia, no intuito de compreender as indicações do texto para a proposição da ação/intenção praticada pelo intérprete. Assim, a ação é intencional no trabalho psicofísico do ator é a ação que conduz o sentimento. Todavia, Thomas afirmou que

O teatro brasileiro não teve a mesma sorte da pintura e das letras em sua abrangência de discussão conceitual. As escolas aqui ainda discutem imbecilidades como

\footnotetext{
4 Trecho da matéria publicada no Jornal O Globo.
} 
stanislavskianismo ou não-stanislavskianismo, o 'trabalho' do ator ainda não tomou proporções do físico-cientista, do criador que arregimenta forças aleatórias de onde quer que seja para penetrar sedutoramente na alma de seu povo (THOMAS, 1996c ${ }^{5}$, p. 170).

O processo de preparação do ator para alcançar as interpretações que Thomas idealiza compreende um intenso trabalho para 'desnudar' o corpo do intérprete dos bloqueios psicofísicos que possam restringir a plasticidade de sua atuação. Sílvia Fernandes (1996) investigou com afinco os procedimentos utilizados por Thomas para a direção dos atores. A autora se deteve especialmente no espetáculo Carmem com filtro $2^{6}$, sob uma análise na atuação de Bete Coelho interpretando a personagem Carmem. Na etapa inicial, Thomas elimina as técnicas de atuação às quais a atriz estava habituada: "O processo de desconstrução principia com a desestruturação dos esquemas corporais rotineiros e a desestabilização dos códigos de interpretação já introjetados" (FERNANDES, 1996, p. 98).

Deste modo, torna-se evidente que o treinamento consistiu basicamente em estimular o novo, o completamente novo, no qual "[...] todas as certezas técnicas, metodológicas ou teóricas que o ator possa trazer de seu aprendizado anterior são sistematicamente demolidas" (FERNANDES, 1996, p. 98). O trabalho pré-cênico é justamente esse, o de desconstruir para construir. Thomas adota procedimentos específicos para o refinamento do aparato físico e vocal da intérprete, objetivando uma conscientização e potencialização dos recursos de expressão da atriz. "Eu pego pelo braço, marco todos os movimentos, dou a musicologia do texto que ainda não veio, mexo na cara, na sobrancelha, ensino como tensionar o corpo para aquele momento específico. O ator aprende aquilo e aprende a se sentir orgânico dentro disso, dia após dia" (THOMAS7, 1989 apud FERNANDES, 1996, p. 100).

Assim, é como se a atriz fosse sendo pincelada aos poucos, o diretor se torna um pintor, cada detalhe é construído meticulosamente, concretizando numa partitura corporal integral. "A Bete Coelho era dirigida milimetricamente: 'agora respire, agora ponha a mão no chão, agora grave, grave, grave, agora sobe, sobe, sobe' " (DAMAS$\mathrm{CENO}^{8}, 1994$ apud FERNANDES, 1996, p. 101). Nesse sentido, o trabalho do ator fica num primeiro momento mais a cargo do encenador, pois somente com as diretrizes precisas do 'progenitor' da cena é que o ator poderá conceber a construção da personagem. Obviamente, o ator não se torna uma 'marionete', mas ele elabora e personifica sua atuação a partir de um rigoroso treinamento, sob as orientações do encenador. Para tanto,

O ator tem de ter boa dose de disponibilidade para trabalhar com Gerald Thomas. As personagens que ele inventa não são simples nem fáceis. Impossível lembrar de uma

\footnotetext{
5 Trecho da matéria publicada no jornal Folha de São Paulo.

6 O espetáculo Carmem com filtro 2 estreou em outubro de 1988 no La Mamma (Nova York) e no Brasil em março de 1989 no Teatro Nelson Rodrigues (Rio de Janeiro). Segundo Sílvia Fernandes (1996), a atriz Bete Coelho, trabalhando com Thomas desde a primeira montagem de Carmem, sintetizava naquele momento tudo aquilo que Gerald esperava de um ator.

7 Gerald Thomas em "carta ao crítico Marco Veloso", de 14 de dezembro de 1989.

8 Luiz Damasceno, em entrevista concedida a Sílvia Fernandes em 26 de julho de 1994. Luiz é professor da Escola de Arte Dramática - EAD da Universidade do Estado de São Paulo - USP e ator, tendo trabalhado 16 anos com Gerald Thomas.
} 
ao menos que andasse em linha reta, como um ser humano normal, sem quebrar o eixo do corpo em ângulos improváveis. [...] Figuras sem sensualidade, esquálidas, desvitalizadas. Maquilagens carregadas, rostos retintos de branco, como máscaras de teatro japonês. As marcações são coreográficas. Quase sempre desenhadas em linhas paralelas e com acentuado uso de diagonais (GUZIK, 1996, p. 208).

A atriz Bete Coelho compôs "[...] o gesto e o movimento através de tensões concentradas em áreas específicas dos músculos que indicam os respectivos estados emocionais" (FERNANDES, 1996, p. 130). Desta maneira, parece não existir elementos corporais supérfluos, a composição da partitura corpórea tem por finalidade a qualidade de clareza do movimento. O resultado desse procedimento acarreta numa interpretação sem excessos, com ênfase para cada gesto, movimentos determinados, nunca arbitrários. A interpretação de Carmem se mostra em cena com "[...] sequências abruptas por onde irrompem as situações diferenciais ou as variações qualitativas da personagem. Um corte brusco separa uma sequência da outra, como se um determinado esquema de emoção explodisse [...]" (FERNANDES, 1996, p. 109).

No caso da personagem Carmem, as referências para a construção do papel estão superpostas no gesto da primeira Carmem de Prosper Merimée, criada num conto breve de 1845, destacando a figura da mulher fatal que destrói a vida de um tenente denominado José; e especialmente no enredo da ópera de Bizet. Além disso, as citações da narrativa operística a Helena grega, mítica causadora da Guerra de Tróia, e a Helena do Fausto de Goethe são agregadas para a composição da personagem (FERNANDES, 1996).

Como se nota, a construção da figura de Carmem resultou numa personagem justaposta de fragmentos, numa aglutinação de várias personagens numa só. O procedimento intertextual supõe uma atitude diferente frente à cena, incita o espectador a abrir-se para a leitura da personagem, para construir sentidos e se construir enquanto leitor-texto.

Nesse sentido, outra dimensão do trabalho intelectual do público é atualizar a tradição, mesmo que para isso ele se contraponha a alguma de suas certezas e, a partir daí, consiga discernir ou mesmo vislumbrar novas possibilidades de leitura. Afinal, o significado de uma obra não morre, nem se congela: cada momento, cada geração, cada leitor a verá de um ângulo singular. É próprio do olhar perceptivo apontar como se constituí a nova perspectiva, e o que ela realmente pode acrescentar de novo. O trabalho do espectador de fato é cumulativo, devido à consciência individual histórica que o precede.

No campo dos significados, a compreensão da cena será sempre a partir de múltiplos olhares, jamais a partir de uma única interpretação. Por isso, é possível afirmar que não existe uma leitura singular e homogênea por parte do público. A função da obra de arte não é transmitir um significado conceitual determinado, seu sentido irá ser completado segundo as próprias peculiaridades da plateia. Assim, o espectador constrói progressivamente novos conhecimentos, novas formas de pensar e de relacionar experiências teatrais anteriores com as novas. Com certeza, o sentido da cena é dado fundamentalmente pelo espectador no trabalho de Thomas.

O encenador Gerald Thomas concretiza seus espetáculos a partir de um arcabouço histórico de referências, abrindo espaço para o espectador dialogar com um território sem delimitação. A escrita cênica de Thomas, através do jogo metafórico, da identidade visual de suas montagens e da complexidade da sua linguagem, registrou a sua marca na plataforma teatral brasileira. As proposições deste artista com 
obras multifacetadas contribuíram e influenciaram de forma significativa as produções cênicas nacionais por longos anos. Ele revolucionou o teatro de seu tempo com resultados surpreendentes, criando uma estética pouco compreendida à época, e desta forma, suas encenações são de suma relevância porque instigam estudos por uma nova configuração cênica.

\section{Referências}

FERNANDES, Sílvia; GUINSBURG, Jacó. (orgs.) Um encenador de si mesmo: Gerald Thomas. São Paulo: Perspectiva, 1996. (Signos, 21)

FERNANDES, Sílvia. Memória e invenção: Gerald Thomas em cena. São Paulo: Perspectiva, 1996. (Coleção estudos, 149)

FORJAS, Cibele. A linguagem da luz: a partir do conceito de pós-dramático desenvolvido por Hans-Thies Lehmann. In: FERNANDES, Sílvia; GUINSBURG, Jacó. O Pós-dramático: um conceito operativo? São Paulo: Perspectiva, 2010. (Coleção debates)

GUZIK, Alberto. Digressão ao redor de um inventor de si mesmo. In: FERNANDES, Sílvia; GUINSBURG, Jacó. (orgs.) Um encenador de si mesmo: Gerlad Thomas. São Paulo: Perspectiva, 1996. (Signos; v.21)

LEHMANN, Hans-Thies. O teatro pós-dramático. São Paulo: Cosac \& Naify, 2007.

ROSÁRIO FILHO, Luiz Macksen do. O século em pedaços de Gerald. Jornal do Brasil, Rio de Janeiro, 19 agosto 2000. Caderno B, p. 3.

STANISLAVSKI, Constantin. A criação de um papel. Tradução de: Pontes de Paula Lima. 14. ed. Rio de Janeiro: Civilização Brasileira, 2010.

SZONDI, Peter. Teoria do drama moderno [1880-1950]. Tradução de: Luiz Sergio Repa. São Paulo: Cosac \& Naify, 2001.

THOMAS, Gerald. Gerald Thomas e a arte da encenação. In: FERNANDES, Sílvia; GUINSBURG, Jacó. (orgs.) Um encenador de si mesmo: Gerald Thomas. São Paulo: Perspectiva, 1996a. (Signos, 21)

THOMAS, Gerald. O Blá Blá Blá na ribalta. In: FERNANDES, Sílvia; GUINSBURG, Jacó. (orgs.) Um encenador de si mesmo: Gerald Thomas. São Paulo: Perspectiva, 1996b. (Signos, 21)

THOMAS, Gerald. A bandeira de lugar nenhum. In: FERNANDES, Sílvia; GUINSBURG, Jacó. (orgs.) Um encenador de si mesmo: Gerald Thomas. São Paulo: Perspectiva, 1996c. (Signos, 21)

UBERSFELD, Anne. Para ler o teatro. Tradução de: José Simões (coord.). São Paulo: Perspectiva, 2005. 